\title{
Late-Onset Disseminated Superficial Actinic Porokeratosis in an Elderly Woman
}

Aida Khaled · Mouna Kourda · Fadoua Abdelmoula · Lilia M'ssedi · Mohamed Nejib Tougourti · Mohamed Ridha Kamoun

To view enhanced content go to www.dermtherapy-open.com Received: April 1, 2011 / Published online: May 20, 2011

(C) The Author(s) 2011. This article is published with open access at Springerlink.com

\section{ABSTRACT}

Introduction: Disseminated superficial actinic porokeratosis (DSAP) is the most common form of porokeratosis. A case of late-onset DSAP is reported with an uncommon presentation in an elderly patient. Methods: An 80-year-old woman, with diabetes mellitus treated with metformin, and hypertension treated with metoprolol and captopril, presented with multiple $2 \mathrm{~mm}$-to-7 $\mathrm{cm}$ brown patches, for 5 years. The patches were often confluent with an atrophic center and a well-demarcated keratotic border located on the

Aida Khaled $(\bowtie) \cdot$ Mohamed Ridha Kamoun Department of Dermatology, Boulevard 9 Avril Tunis, Charles Nicolle Hospital, Tunis, Tunisia 1006. Email: aida.khaled@rns.tn

Mouna Kourda

Department of Dermatology, Razi Hospital, La Manouba, Tunisia

Fadoua Abdelmoula

Dermatology Consultation of Khereddine Hospital, Tunisia

Lilia M'ssedi

SOS Elderly Patients, La Manouba, Tunisia

Mohamed Nejib Tougourti

Department of Internal Medicine, Razi Hospital,

La Manouba, Tunisia thighs, lower legs, and feet. Results: Histological examination of a cutaneous biopsy showed the presence of rare cornoid lamellae, confirming the clinical diagnosis of DSAP. Conclusion: In this report, the atypical presentation of DSAP is discussed in this elderly patient and also the possible triggering factors at this age.

Keywords: case study; disseminated superficial actinic porokeratosis; elderly

\section{INTRODUCTION}

Porokeratosis (PK) is a heterogeneous group of hereditary or acquired disorders, with a broad clinical spectrum and various etiologies. It manifests clinically with patches surrounded by a keratotic border, usually more palpable than visible, and an atrophic depressed center. ${ }^{1}$ Histologically, the hallmark of PK is cornoid lamella, which corresponds to a thin column of parakeratotic cells above an invaginated epidermis devoid of an underlying granular layer. Cornoid lamella corresponds to the hyperkeratotic border and is thought to be a focal clonal proliferation of keratinocytes. ${ }^{2,3}$ Several subtypes of PK have been distinguished based on size, localization, and number of lesions: classic 
PK of Mibelli, disseminated superficial actinic PK (DSAP), disseminated superficial PK (DSP), linear PK, PK palmaris et plantaris disseminata, and punctuate palmoplantar PK.,3 The pathogenesis of PK is still unknown but it is now considered as a genodermatosis with an autosomal dominant mode of inheritance. ${ }^{2}$

DSAP is the most common form of PK. It mainly involves fair-skinned women and usually occurs by the third or the fourth decade. ${ }^{3}$ Cutaneous lesions are usually located in photoexposed areas, mainly extremities, and are usually multiple (in the hundreds) and smallsized $(<2 \mathrm{~cm})$. An atypical presentation of DSAP characterized by a late onset is reported in an elderly patient with unusually large lesions.

\section{REPORT}

An 80-year-old woman (skin type 4) with no excessive sun exposure, with type 2 diabetes mellitus treated with metformin for 20 years and hypertension treated with metoprolol and captopril for 10 years, presented for 5 years with pruritic lesions of the legs. Informed consent was obtained from the patient. There were no similar familial cases. Her daughter denied any cutaneous disorder in the years preceding the onset of the presented lesions. Cutaneous examination showed on the thighs, lower legs, and feet; multiple $2 \mathrm{~mm}$-to- $7 \mathrm{~cm}$ brown plaques, sometimes confluent with an atrophic and desquamative center and well-demarcated keratotic and filiform border (Figure 1a, 1b, 1c). The rest of the tegument was normal, particularly the mucous membranes, palms of hands, and soles of feet. Physical examination was otherwise normal. Histological examination of a cutaneous biopsy showed an atrophic epidermis with the presence of rare cornoid lamellae presenting as thin columns of parakeratin over a focal invagination of epidermis with loss of granular
Figure 1a, b and c. Multiple $2 \mathrm{~mm}$-to- $7 \mathrm{~cm}$ brown patches, sometimes confluent with an atrophic center, and a well-demarcated keratotic border located on the thighs (a), lower legs (b), and feet (c).
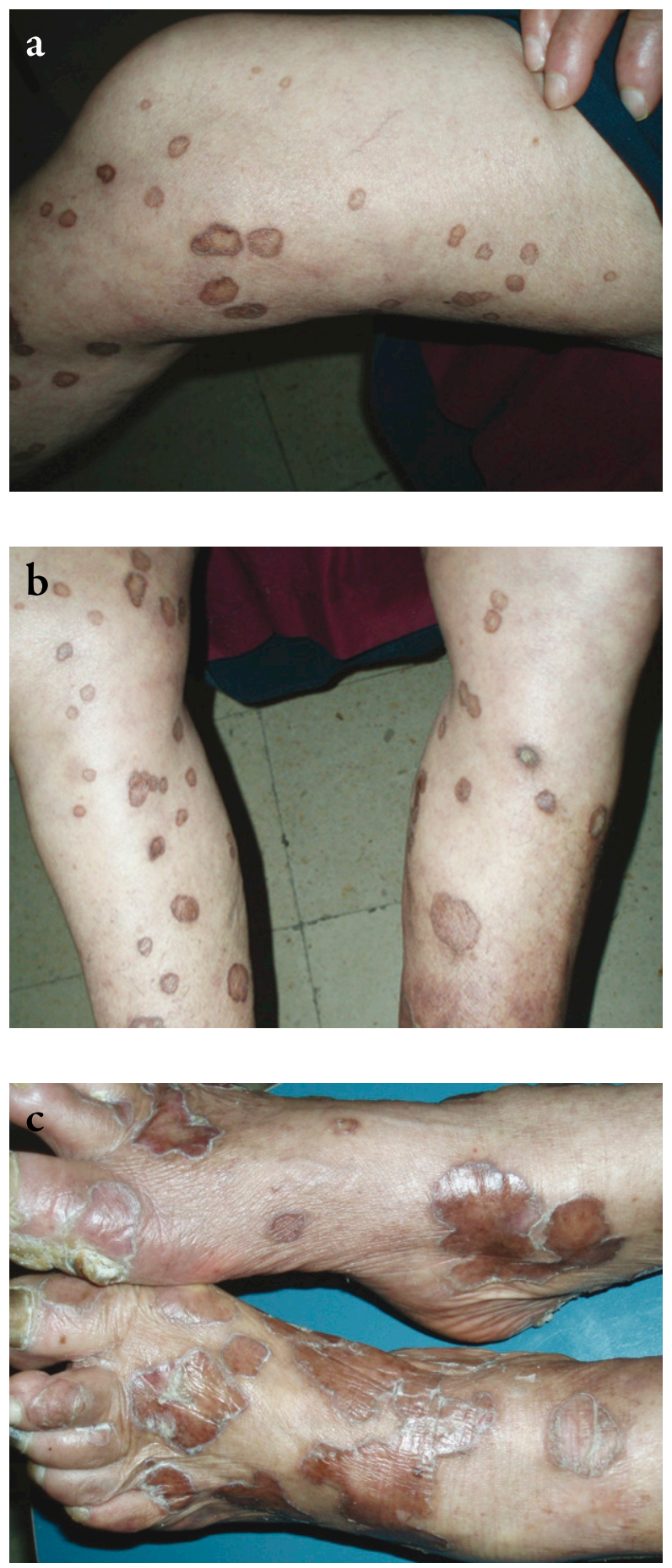

layer and apoptotic keratinocytes (Figure 2). These histological features confirmed the clinical 
Figure 2. Cornoid lamella presenting as a thin column of parakeratin over a focal invagination of an atrophic epidermis with loss of granular layer and apoptotic keratinocytes.

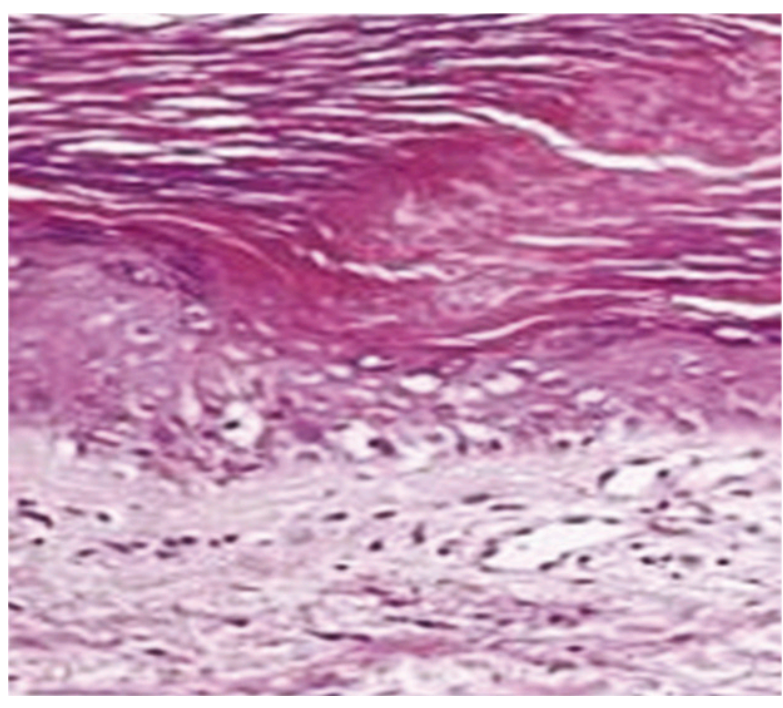

diagnosis of PK in its particular form of DSAP. Laboratory tests revealed no significant findings. The patient had topical keratolytics with no improvement.

\section{DISCUSSION}

The patient within this case study had a lateonset DSAP (at 75 years of age) which is a known but rarely reported phenomenon. ${ }^{4}$ DSAP is an inherited autosomal dominant condition with reduced penetrance at younger ages. Indeed, the disorder requires sun exposure for full expression and it usually begins in the third to fourth decade, but rarely at later ages.,4 Chronic exposure to sunlight is an important triggering factor for full expression of DSAP. This is illustrated by the relative frequency of this disorder in geographical areas with large amounts of sun exposure, particularly Australia. ${ }^{3}$ Shumack and Commens even stated that in patients with sun-damaged skin lesions, DSAP is commonly mistaken for multiple actinic keratoses. $^{3}$
Localization on lower limbs with no involvement of the face should indicate the diagnosis of DSAP, rather than actinic keratosis. The onset of DSAP in elderly patients can be explained by the fact that the pathologic clone for PK is present but remains latent until the amount of sun exposure brings about its proliferation. ${ }^{4}$ The elderly patient within this study is sun protected most of the time; she is a housewife, so she spends most of the day indoors. This can explain the delayed expression of DSAP. The physiological lowering of the immunocompetence due to age can be another triggering factor of delayed expression of DSAP in adulthood.

Patrizi et al. reported 12 cases of DSAP in elderly patients aged between 70 to 90 years old ( 2 males and 10 females) with a mean age at onset of about 70 years old. ${ }^{4}$ In this report, the clinical picture was similar to that of the patient within this case report with an exclusive involvement of the lower limbs. The authors stated that lateonset DSAP described in their patients may represent a type of immunosuppression-induced PK. This latter had already been described either after organ transplantation (especially kidney and bone marrow transplantations), long-term use of corticosteroids, or in AIDS. ${ }^{2,5,6}$ Recently, with the widespread use of organ transplantation and immunosuppressive treatments, the incidence of PK has increased from $0.34 \%$ to $10.68 \%$ of patients who have undergone organ transplantation. ${ }^{7}$

The elderly patient in this case study did not have any immunosuppressive drugs, but she had diabetes mellitus which can contribute to and aggravate the age-related immunosuppression. The mechanism of immunosuppression-induced PK remains unclear, but it has been hypothesized that loss of immunosurveillance caused by immunosuppression allows the proliferation of abnormal keratinocyte clones, which leads to PK. ${ }^{8}$ 
Moreover, PK develops due to higher rates of mitotic division in abnormal clones than in normal keratinocytes. ${ }^{6}$ Most porokeratoses described after immunosuppression were of DSP subtype. However, there have been rare cases of immunosuppression-induced DSAP described. ${ }^{9}$ The diagnosis of DSP is unlikely in the patient, due to the predominant localization on the lower limbs with sparing of the face and the trunk. Cutaneous lesion size in the patient was important, especially on the dorsum of the feet and the lower legs, while more typical in patients with DSAP, the lesions were small in size on the thighs. To be in the conventional classification of $\mathrm{PK}$, the patient was considered as having DSAP and the huge lesions were due to the confluence of the patches. Drug-induced DSAP seems to be unlikely in the patient, due to the long delay between the ingestion of the drugs (antidiabetic and antihypertensive drugs) and the onset of the lesions. Drug-induced PK has been rarely reported in the literature. Incriminating drugs were thiazidic derivative, suramine, and antibiotics. ${ }^{10-12}$ In all reported cases, delay between drug administration and onset of PK was short: between 10 to 15 days.

Different therapeutic modalities were attempted in DSAP with variable results. These treatments are either topical (keratolytics, 5-fluorouracil 5\%, vitamin D3 analogs), physical (photodynamic therapy, Q-switched laser, $\mathrm{CO}_{2}$ laser), or systemic (oral acitretin), and their use remains largely in the field of anecdotal experience. The precise value of each therapeutic modality is presently difficult to determine owing to the paucity of controlled studies. ${ }^{1}$ The patient was topically treated with keratolytics with no real improvement.

PK is a chronic disorder known to be a precursor of squamous-cell carcinoma. Malignant transformation can occur in 3.4\% (DSAP) to $19 \%$ (linear PK) of cases. ${ }^{2}$ The higher incidence of skin carcinoma may be due to multiple factors, such as earlier onset, larger size, and the underlying genetic predisposition related to loss of heterozygosity. ${ }^{2,5}$ Long-term surveillance is then warranted in all patients with PK. Surprisingly, there is no increase in skin cancers arising in PK lesions in individuals who have undergone organ transplantation, who are at higher risk for skin cancers otherwise. ${ }^{2}$

\section{CONCLUSION}

In conclusion, clinicians should be aware of the possible late onset of DSAP, especially in dark-skinned elderly people with no history of intensive sun exposure. Risk factors seem to be related to ultraviolet radiations, agerelated immunosuppression, and probably, although rare, some drugs, in particular immunosuppressive drugs.

\section{ACKNOWLEDGMENTS}

Dr. Khaled declares that there is no funding or sponsorship received in relation to this paper. The authors declare that they have no conflicts of interest. Dr. Khaled is the guarantor for this article, and takes responsibility for the integrity of the work as a whole.

Open Access. This article is distributed under the terms of the Creative Commons Attribution Noncommercial License which permits any noncommercial use, distribution, and reproduction in any medium, provided the original author(s) and source are credited.

\section{REFERENCES}

1. Skupsky H, Skupsky J, Goldenberg G. Disseminated superficial actinic porokeratosis: a treatment review. J Dermatolog Treat. 2010;Oct 22 [Epub ahead of print]. 
2. Murase J, Gilliam AC. Disseminated superficial actinic porokeratosis co-existing with linear and verrucous porokeratosis in an elderly woman: update on the genetics and clinical expression of porokeratosis. J Am Acad Dermatol. 2010;63:886891.

3. Shumack SP, Commens CA. Disseminated superficial actinic porokeratosis: a clinical study. J Am Acad Dermatol. 1989;20:1015-1022.

4. Patrizi A, D'Acunto C, Passarini B, Neri I. Porokeratosis in the elderly: a new subtype of disseminated superficial actinic porokeratosis. Acta Derm Venereol. 2000;80:320-324.

5. Kanitakis J, Euvrard S, Faure M, Claudy A. Porokeratosis and immunosuppression. Eur J Dermatol. 1998;8:459-465.

6. Cha SH, Park HT, Lee JY, Cho BK. Atypical porokeratosis developing following bone marrow transplantation in a patient with myelodysplatic syndrome. Ann Dermatol. 2010;22:206-208.

7. Alexis AF, Busam K, Myskowski PL. Porokeratosis of Mibelli following bone marrow transplantation. Int J Dermatol. 2006;45:361-365.

8. Levin RM, Heymann WR. Superficial disseminate porokeratosis in a patient with myelodysplastic syndrome. Int J Dermatol. 1999;38:138-139.

9. Buhl T, Wienrich BG, Sieblist C, Schön MP, Seitz CS. Development of segmental superficial actinic porokeratosis during immunosuppressive therapy for pemphigus vulgaris. Acta Derm Venereol. 2010;90:212-213.

10. Hwang SM, Choi EH, Ahn SK. Disseminated superficial actinic porokeratosis like drug eruption: a case report. J Korean Med Sci. 1999;14:227-229.

11. Goulding JM, Teoh JK, Carr RA, Humphreys F, Gee BC. Eruptive disseminated superficial porokeratosis with rapid resolution: a drug induced phenomenon? Clin Exp Dermatol. 2009;34:895897.

12. O'Donnell BP, Dawson NA, Weiss RB, et al. Suramin-induced skin reactions. Arch Dermatol. 1992;128:75-79. 